\title{
PI3K $\beta$ inhibitor AZD6482 exerts antiproliferative activity and induces apoptosis in human glioblastoma cells
}

\author{
PENG-FEI XU* ${ }^{*}$, JI-AN YANG ${ }^{*}$, JUN-HUI LIU, XUE YANG, JIAN-MING LIAO, \\ FAN-EN YUAN, BAO-HUI LIU and QIAN-XUE CHEN \\ Department of Neurosurgery, Renmin Hospital of Wuhan University, Wuhan, Hubei 430060, P.R. China
}

Received May 31, 2018; Accepted October 30, 2018

DOI: $10.3892 /$ or.2018.6845

\begin{abstract}
Glioblastoma is the most common type of primary brain tumour in adults, and its pathogenesis is particularly complicated. Among the many possible mechanisms underlying its pathogenesis, hyperactivation of the PI3K/Akt pathway is essential to the occurrence and development of glioma through the loss of PTEN or somatic activating mutations in PIK3CA. In the present study, we investigated the effect of the PI3K $\beta$ inhibitor AZD6482 on glioma cells. The CCK-8 assay showed dose-dependent cytotoxicity in glioma cell lines treated with AZD6482. Additionally, AZD6482 treatment was found to significantly induce apoptosis and cell cycle arrest as detected using flow cytometry. Moreover, as shown using western blot analysis, the levels of p-AKT, p-GSK-3 $\beta, \mathrm{Bcl}-2$, and cyclin D1 were decreased after AZD6482 treatment. In addition, we found that AZD6482 inhibited the migration and invasion of glioma cells as detected by wound healing and Transwell invasion assays. Taken together, our findings indicate that AZD6482 exerts an antitumour effect by inhibiting proliferation and inducing apoptosis in human glioma cells. AZD6482 may be applied as an adjuvant therapy to improve the therapeutic efficacy of glioblastoma treatment.
\end{abstract}

\section{Introduction}

Glioma is the most common intracranial tumour. It is assigned grades I-IV according to the WHO Classification of Tumours of the Central Nervous System (1). Among the different types of glioma, glioblastoma multiforme (GBM) is the most common type of primary brain tumour in adults, and it is associated with

Correspondence to: Professor Qian-Xue Chen, Department of Neurosurgery, Renmin Hospital of Wuhan University, 9 Zhangzhidong and 238 Jiefang Roads, Wuchang, Wuhan, Hubei 430060, P.R. China

E-mail: chenqx666@whu.edu.cn

${ }^{*}$ Contributed equally

Key words: glioblastoma, AZD6482, PTEN, PIK3CB, apoptosis, proliferation a poor prognosis (2). Patients with glioblastoma multiforme usually survived less than 15 months following diagnosis and treatment (3). There are no adequate treatment methods for this disease. Currently, a comprehensive approach, including surgery, radiation therapy and chemotherapy, is the main glioma treatment strategy (4). Although tremendous progress has been made in the genomic, transcriptomic and epigenetic fields regarding glioma, the exact pathogenesis of glioma remains unknown (5). Most current research on high-grade glioma has focused on DNA mismatch repair, a disorder of signalling pathways, mutations of PI3K/AKT/PTEN, Ras and P53/RB1 pathway genes and stem cell tumours $(6,7)$.

The PI3K signalling pathway plays a critical role in cell proliferation, differentiation, apoptosis, and glucose transport. The Class I PI3Ks are composed of a regulatory and a catalytic subunit and are further divided into class Ia and class Ib. The regulatory subunits of class Ia PI3Ks included p110 $\alpha$ and p1 $10 \beta$ and are expressed by corresponding genes (PIK3CA and PIK3CB) (8). Deregulation of the PI3K/AKT/mTOR signalling pathway has been demonstrated to result mainly from frequent inactivation of PTEN, which has been identified in at least $60 \%$ of glioblastomas (9). Additionally, mutations in PIK3CA have also been confirmed to exist in glioblastoma. These alterations of genes are associated with tumourigenesis, and relevant studies have revealed the importance of inhibitors targeting the PI3K/Akt/mTOR pathway.

Although mutations in PIK3CA are generally considered to be related to tumourigenesis (10-12), recent research has shown that $110 \beta$ plays an essential role in specific PTENdeficient cancer cells (13-16). In order to investigate whether an inhibitor of p110 $\beta$ could be used to treat glioma, AZD6282, a novel potential selective $\mathrm{p} 110 \beta$ inhibitor, was selected to test its inhibitory properties in glioma U87 and U118 cell lines.

\section{Materials and methods}

Analysis of TCGA and GDSC data. Mutation data from 273 samples were downloaded from the cBioPortal online platform (www.cbioportal.org). The data visualization was performed using the R package ('complexheatmap'). The Genomics of Drug Sensitivity in Cancer (GDSC) database (www.cancerrxgene.org) was used to search for compounds with significant selectivity for PTEN mutations. Scatter plots were generated via the GDSC online platform. 
Cell culture. Human glioblastoma cell lines (U87 and U118) were acquired from the State Key Laboratory of Molecular Biology, Institute of Biochemistry and Cell Biology, Shanghai Institutes for Biological Sciences, Chinese Academy of Sciences (Shanghai, China). The U87 cell line has been found to be misidentified and originate from an unknown glioblastoma. Additionally, the U118 cell line had similar cytogenetics and derivative marker chromosomes with the glioblastoma cell line U138MG. However, our U87 and U118 cell lines were authenticated by STR profiling; thus, we used U87 and U118 as our experimental cells. The cells were cultured in Dulbecco's modified Eagle's medium (DMEM) supplemented with $10 \%$ foetal bovine serum (FBS) (both from Gibco; Thermo Fisher Scientific, Inc, Waltham, MA, USA), $100 \mu \mathrm{g} / \mathrm{ml}$ penicillin and $100 \mu \mathrm{g} / \mathrm{ml}$ streptomycin (Sigma-Aldrich; Merck KGaA, Darmstadt, Germany) at $37^{\circ} \mathrm{C}$ with $5 \% \mathrm{CO}_{2}$.

Chemicals and antibodies. AZD6482 (Fig. 2A) was purchased from MedChemExpress (MCE, Shanghai, China) and dissolved in dimethyl sulfoxide (DMSO), which was purchased from Merck KGaA. Antibodies against phospho-GSK-3 $\beta$ (catalog number: 5558), GSK-3 $\beta$ (catalog number: 9315), Akt (catalog number: 4691), phospho-Akt (catalog number: 4060), Bcl-2 (catalog number: 2872), Bax (catalog number: 2774), cyclin D1 (catalog number: 2922), $\beta$-actin (catalog number: 58169) and GAPDH (catalog number: 5174) (all used at 1:1,000) were purchased from Cell Signaling Technology (Danvers, MA, USA).

Cell viability. Cell Counting Kit-8 (CCK-8) (Dojindo, Shanghai, China) was used to determine the inhibitory effect of AZD6482 on the proliferation of the U87 and U118 cells according to the manufacturer's instructions. Cells in Dulbecco's modified Eagle's medium (Gibco; Thermo Fisher Scientific, Inc, Waltham, MA, USA) with 10\% FBS were plated into 96-well plates $\left(5 \times 10^{3}\right.$ cells $/ 100 \mu \mathrm{l} /$ well $)$ and cultured with $0.625,1.25$, $2.5,5,10,20$ or $40 \mu \mathrm{M}$ of AZD6482 for $48 \mathrm{~h}$. Then, $10 \mu \mathrm{l}$ of CCK- 8 was added, and the cells were incubated for another $1 \mathrm{~h}$. The absorbance value (OD) of every well was measured with a spectrophotometric plate reader at $450 \mathrm{~nm}$. Assays were performed in triplicate with three independent experiments.

Colony formation assay. An appropriate number of cells were plated on a 6 -well plate $(500$ cells $/ 2 \mathrm{ml} /$ well $)$ and cultured in $2 \mathrm{ml}$ of DMEM with $10 \%$ FBS. Then, the cells were treated with $5 \mu \mathrm{M}$ of AZD6482 for three weeks until the cells in the plates had formed colonies that were of approximately the correct size (50 cells per colony or greater). The cells were fixed with $2 \mathrm{ml}$ of $75 \%$ ethanol at room temperature for $15 \mathrm{~min}$ and then stained with $0.5 \%$ crystal violet. The counts of colonies were quantitatively evaluated using ImageJ Software (National Institutes of Health, Bethesda, MD, USA).

5-Ethynyl-2'-deoxyuridine (EdU) incorporation assay. The Cell-Light $^{\mathrm{TM}}$ EdU Apollo $^{\circledR} 643$ In Vitro Imaging kit (100T) was purchased from RiboBio Co., Ltd. (Guangzhou, China). It was used according to the manufacturer's protocol. In brief, $5 \times 10^{3}$ cells were seeded in a volume of $100 \mu 1$ of DMEM into each well of a 96-well plate and treated with $0,10,20$ or $40 \mu \mathrm{M}$ of AZD6482 for $48 \mathrm{~h}$. Then, the cells were cultured in medium with $50 \mu \mathrm{M}$ EdU for $12 \mathrm{~h}$ and fixed with $4 \%$ paraformaldehyde for $30 \mathrm{~min}$. Cells were incubated in the Apollo reaction mixture for $30 \mathrm{~min}$, and the DNA was stained with $5 \mu \mathrm{g} / \mathrm{ml}$ Hoechst 33342 for $30 \mathrm{~min}$. The fluorescence images were visualized under a fluorescence microscope (magnification, x200; Olympus BX51; Olympus, Tokyo, Japan).

Cell cycle distribution analysis. The effect of AZD6482 on the cell cycle distribution was analysed by flow cytometry with propidium iodide (PI) staining. Cells in 6-well plates were harvested and washed in PBS and then treated with 0 , 10,20 or $40 \mu \mathrm{M}$ AZD6482 for $48 \mathrm{~h}$. Then, the cells were fixed in cold $70 \%$ ethanol for $12 \mathrm{~h}$ at $4^{\circ} \mathrm{C}$. Subsequently, the cells were washed twice with PBS, treated with $50 \mu 1$ of $100 \mu \mathrm{g} / \mathrm{ml}$ RNase at $37^{\circ} \mathrm{C}$ and stained with $5 \mu \mathrm{l}$ of PI from a $50 \mathrm{mg} / \mathrm{ml}$ stock solution. The results were analysed by BD FACSAria (BD Biosciences, Franklin Lakes, NJ, USA). The data were quantified using ModFit LT 4.0 (http://www.vsh.com/products/mflt/index.asp; Verity Software House, Topsham, ME, USA).

Flow cytometric analysis of apoptosis with PE/7-ADD staining. To analyse apoptosis, cells were treated with 0,10 , 20 or $40 \mu \mathrm{M}$ AZD6482 for $48 \mathrm{~h}$. The cells were suspended in $100 \mu \mathrm{l}$ of $1 \mathrm{X}$ binding buffer $(0.1 \mathrm{mM}$ HEPES/NaOH, $1.4 \mathrm{M}$ $\mathrm{NaCl}, 25 \mathrm{mM} \mathrm{CaCl}_{2}, \mathrm{pH} \mathrm{7.4)}$ and stained with $5 \mu \mathrm{l}$ of $\mathrm{PE}$ Annexin $\mathrm{V}$ and $5 \mu \mathrm{l}$ of 7-amino-actinomycin (7-ADD) for $15 \mathrm{~min}$ at room temperature. Then, $400 \mu 1 \mathrm{XX}$ binding buffer was added to each tube. Analysis of the results was carried out with BD FACSAria (BD Biosciences, Franklin Lakes, NJ, USA). Data were quantified with FlowJo software (Tristar, San Carlos, CA, USA).

Wound-healing assay. The cells were seeded into 6-well plates at a density $\left(3 \times 10^{5}\right.$ cells/ well) and grown until they reached $70-80 \%$ confluence as a monolayer. Then, the cell monolayer was gently and slowly scratched using a yellow pipette tip in each well. Subsequently, the cells were gently washed with 1X PBS and cultured in DMEM supplemented with $1 \%$ FBS. Simultaneously, 0 or $10 \mu \mathrm{M}$ of AZD6482 was added to the medium for an additional 24 and $48 \mathrm{~h}$. The images were visualized under a microscope (magnification, x100; Olympus BX51; Olympus, Tokyo, Japan). The gap distance could be quantitatively evaluated using ImageJ Software (National Institutes of Health, Bethesda, MD, USA).

Cell invasion assays. Invasion assays were performed using a Transwell chamber with an $8.0-\mu \mathrm{m}$ pore polycarbonate membrane. First, $8 \times 10^{4}$ cells treated with 0,5 , or $10 \mu \mathrm{M}$ of AZD6482 were seeded into the top chambers and suspended in $100 \mu \mathrm{l}$ of serum-free DMEM. Then, $500 \mu 1$ of $10 \%$ FBS DMEM was added into the lower chamber. After $36 \mathrm{~h}$ of incubation, the cells on the lower side of the insert membrane were fixed with $5 \%$ glutaraldehyde and stained with $0.5 \%$ crystal violet. Finally, the results were visualized under a microscope (magnification, x200; Olympus BX51; Olympus, Tokyo, Japan).

Western blot analysis. Western blotting was performed as described previously (15). Briefly, the cells were treated with 
A

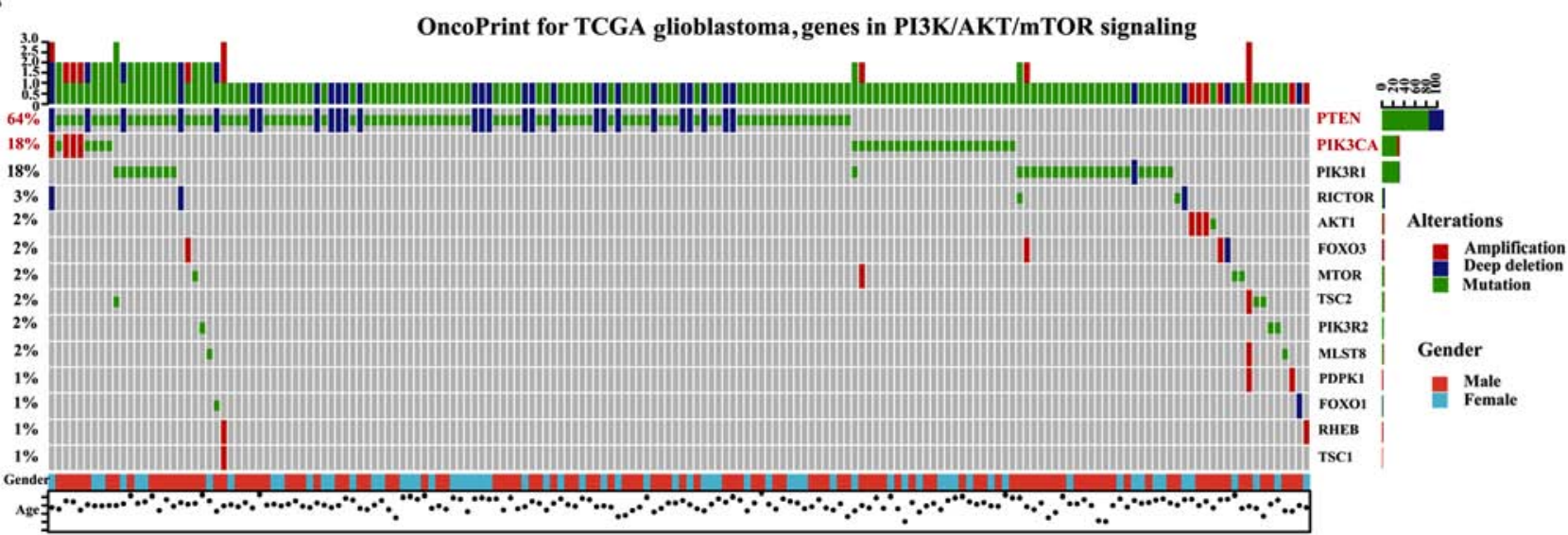

B
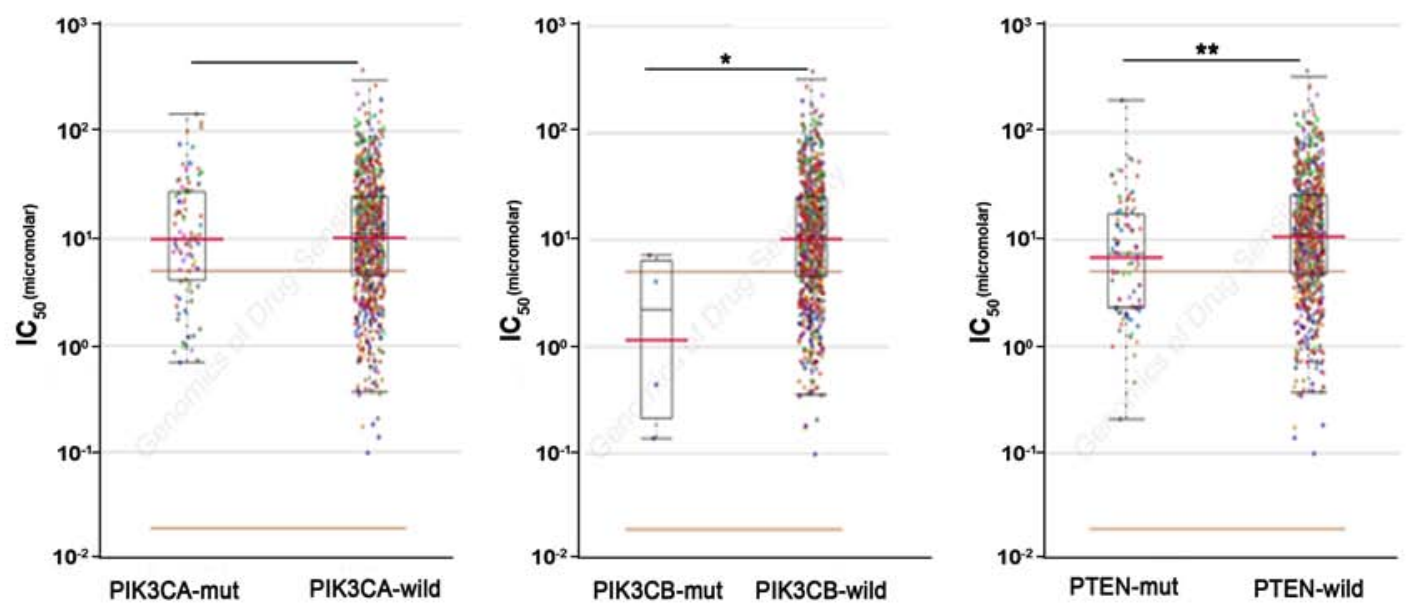

Figure 1. PTEN is frequently mutated in glioblastoma, and cancer cell lines with PTEN mutations were sensitive to AZD6482. (A) Mutation data of glioblastoma from The Cancer Genome Atlas (TCGA) database showed the genetic alteration status of the PI3K signalling pathway. (B) Data of GDSC database showed the relationship between various gene mutations and drug sensitivity. Scatter plot showed IC $_{50}$ values of PIK3CA-mutated, PIK3CB-mutated, PTENmutated and corresponding wild-type cell lines following treatment with AZD6482. Each point represents the $\mathrm{IC}_{50}$ value for an individual cell line. The red lines indicate the geometric mean. The lower and upper lines indicated the minimum and maximum concentration of AZD6482. Mut, mutated; wild, wild-type. ${ }^{*} \mathrm{P}<0.05,{ }^{* *} \mathrm{P}<0.01$

$0,5,10$, or $20 \mu \mathrm{M}$ of AZD6482 for $48 \mathrm{~h}$ and then lysed in RIPA buffer. Then, the same protein samples were loaded onto a 10 or $12 \%$ SDS-PAGE and electrotransferred to a polyvinylidene fluoride (PVDF) membrane for 60 or $90 \mathrm{~min}$. After the transfer, the membrane was blocked with $5 \%$ skim milk and then incubated with anti-Akt, anti-p-Akt, antiGSK-3B, anti-p-GSK-3B, anti-Bcl-2, anti-Bax, anti-cyclin D1, anti- $\beta$-actin and anti-GAPDH antibodies at 1:1000 overnight at $4^{\circ} \mathrm{C}$. Subsequently, the membranes were incubated with Alex Fluor 680/790-labelled goat anti-rabbit or goat anti-mouse IgG secondary antibodies (catalog numbers: 926-68021/926-68020; Li-COR Biosciences, Lincoln, NE, USA) for $1 \mathrm{~h}$. The results were visualized using the LI-COR Odyssey Infrared Imaging System (Li-COR Biosciences).

Statistical analysis. Statistical analyses were conducted using the SPSS 17.0 software package (SPSS Inc., Chicago, IL, USA) and GraphPad Prism 6.0 software (GraphPad Software, Inc., La Jolla, CA, USA). Data from the experiments are expressed as the means \pm standard deviation (SD). Statistical differences between groups were analysed by one-way ANOVA and the
Tukey test. All experiments were repeated at least three times. Statistical significance is indicated in the figures as follows: ${ }^{*} \mathrm{P}<0.05,{ }^{* *} \mathrm{P}<0.01$ and ${ }^{* * *} \mathrm{P}<0.001$.

\section{Results}

Deregulation of the PI3K signalling pathway resulting from frequent mutation of PTEN in glioblastoma cells. Mutation data of glioblastoma were downloaded from the cBioPortal online platform and visualized using the $\mathrm{R}$ package complexheatmap (17-19). Mutation of PTEN (64\%) was found in 273 samples (Fig. 1A). Among them, deep deletion of PTEN was the dominant mutation. Additionally, PIK3CA was also frequently mutated in glioblastoma cells. However, there were few mutations in PIK3CB. We further explored the GDSC database. The datasets showed that PTEN-deficient cancer cells were sensitive to AZD6482 (Fig. 1B) (20).

AZD6482 suppresses the proliferation of U87 and U118 cells. The antiproliferative effect of AZD6482 on U87 and U118 cells was investigated using a Cell Counting Kit-8 (CCK-8). 
A

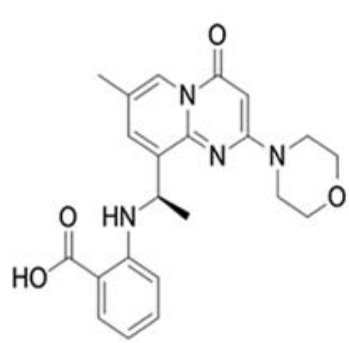

C

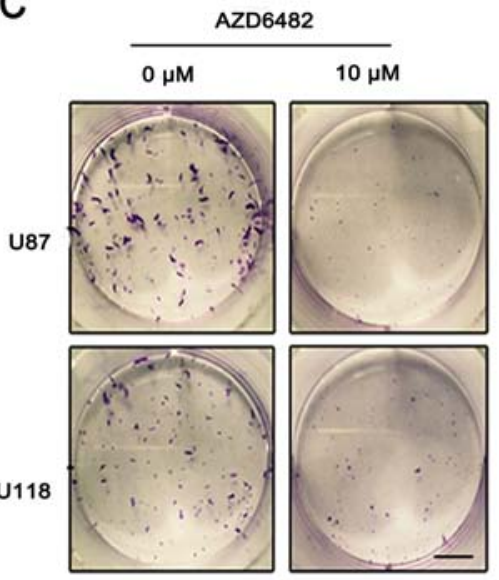

B

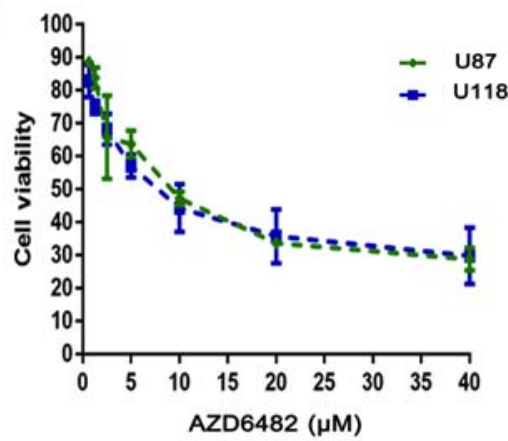

D

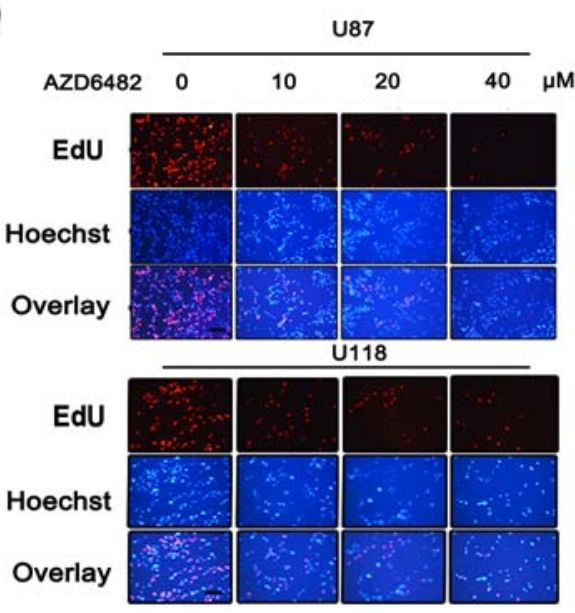

Figure 2. Treatment with AZD6482 leads to an anti-proliferative effect on glioblastoma cells. (A) The molecular structure of AZD6482. (B) Cell viability was determined by CCK-8 assay after AZD6482 treatment at various concentrations $(0,0.625,1.25,2.5,5,10,20$, or $40 \mu \mathrm{M})$ for $48 \mathrm{~h}$. Each cell line was analysed in triplicate. (C) AZD6482 inhibited the colony formation of U87 and U118 cells. Fewer colonies were formed in the treated group compared with the control group. Scale bar, $50 \mu \mathrm{m}$. (D) DNA replication activity was assessed by an EdU incorporation assay. Nuclei were stained with Hoechst (blue), and the proliferative cells were dyed red with EdU. Scale bar, $100 \mu \mathrm{m}$ (same magnification in all panels).

A

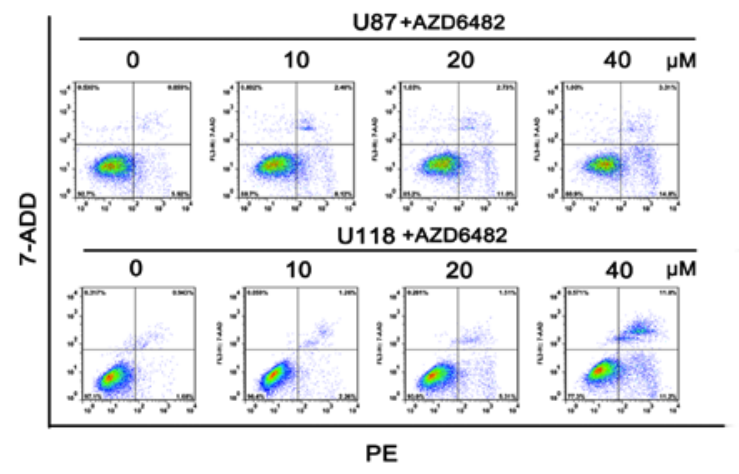

B

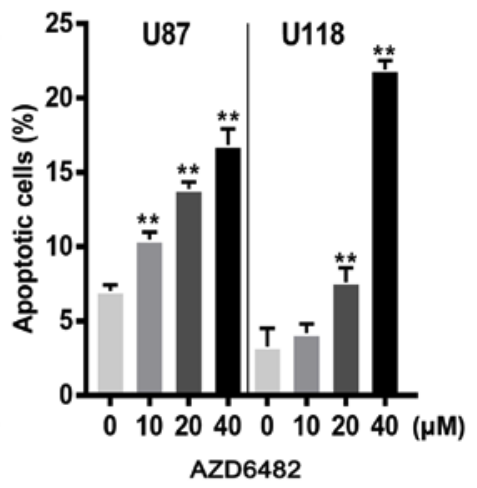

C

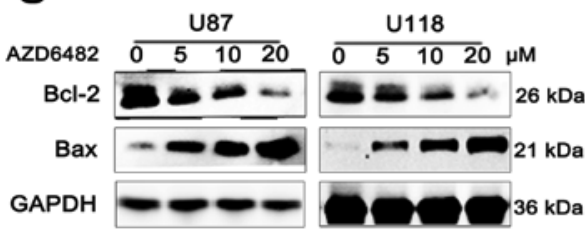

D

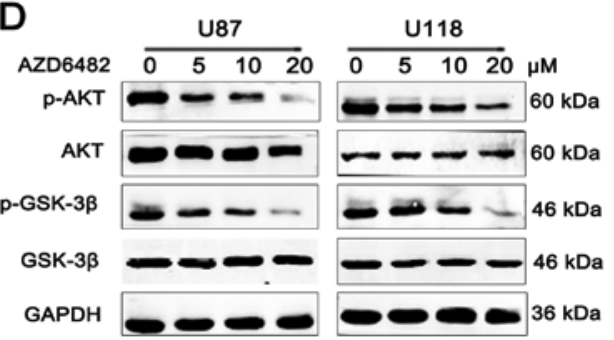

Figure 3. AZD6482 induces apoptosis in U87 and U118 cells. (A) U87 and U118 cells were treated with increasing concentrations of AZD6482 for 48 h, which was followed by an analysis of apoptosis by staining with 7-ADD/PE. (B) Apoptotic cells were measured by flow cytometry. ${ }^{* *} \mathrm{P}<0.01$, compared with that of untreated controls $(0 \mu \mathrm{M})$. Data are presented as the mean \pm SD of at least three independent experiments. The expression levels of $(C)$ Bcl-2, Bax and (D) related proteins of the PI3K signalling pathway were used to assess the inhibitory effect of AZD6482. Each protein was analysed in triplicate, and a representative experiment is shown. 
A

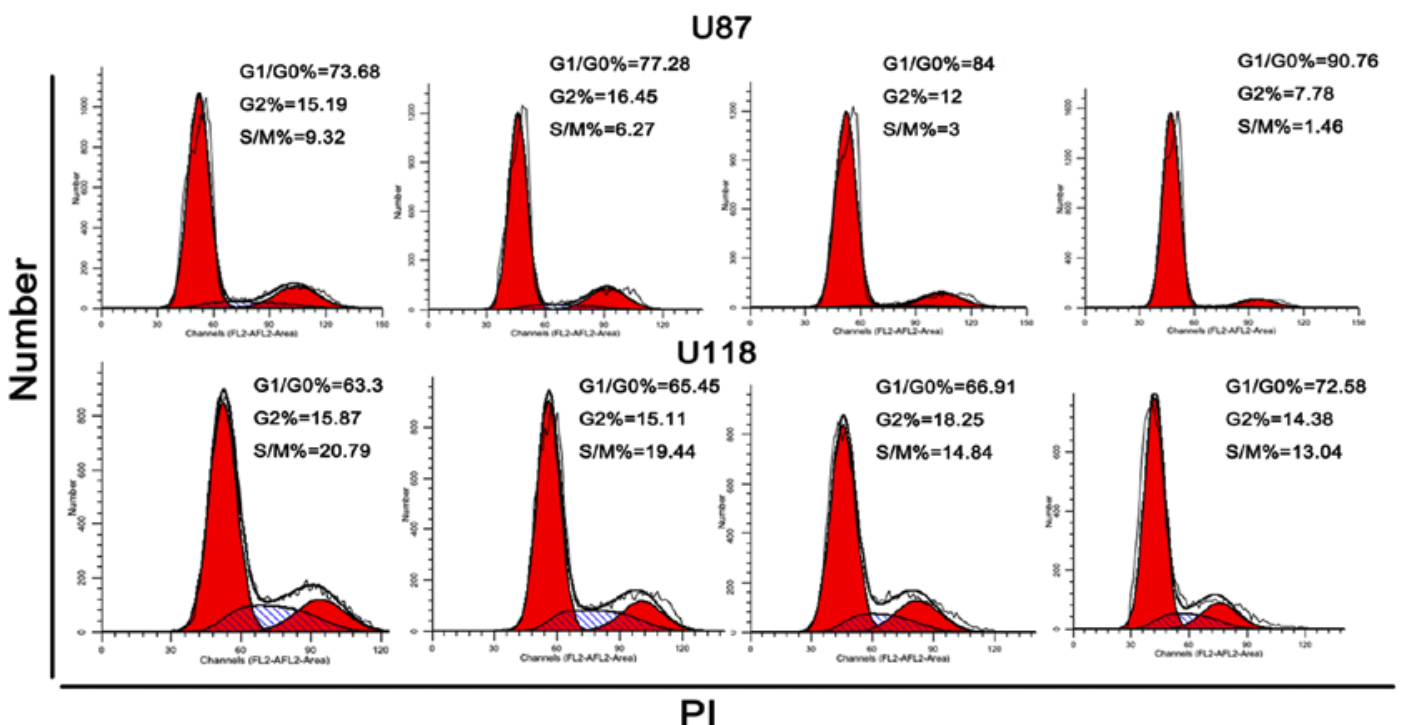

B

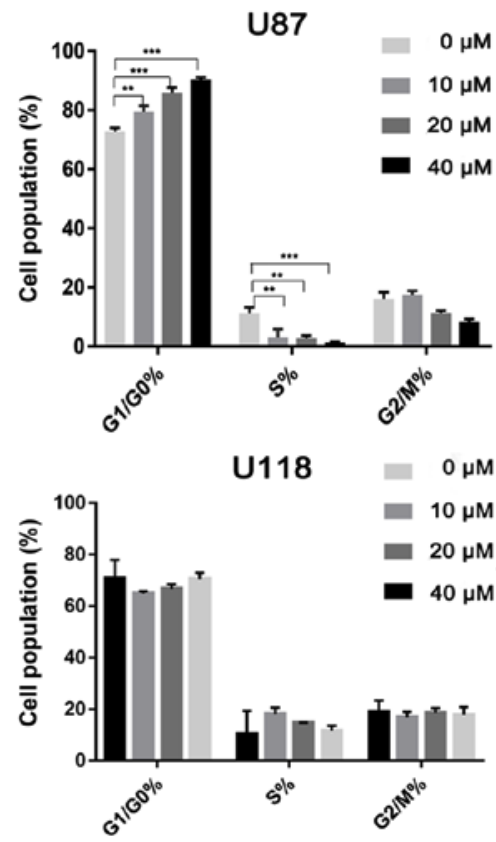

C

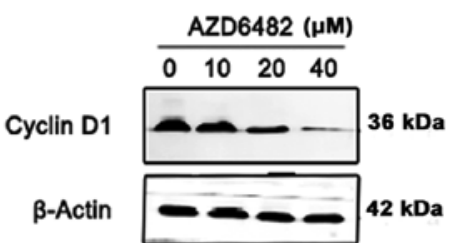

Figure 4. AZD6482 induces cell cycle arrest at the G1 phase in U87 cells. (A) Cell cycle distribution analysis by flow cytometry. AZD6482-induced G1 phase arrest in U87 cells after exposure to AZD6482 (0-40 $\mu \mathrm{M})$ for $48 \mathrm{~h}$. (B) The percentage of the cell population in G1/G0, S and G2/M phases. Data are presented as the mean $\pm \mathrm{SD}$ of at least three independent experiments $(\mathrm{n}=3)$. ${ }^{* *} \mathrm{P}<0.01,{ }^{* * *} \mathrm{P}<0.001$, compared with the untreated controls $(0 \mu \mathrm{M})$. $(\mathrm{C})$ The effects of AZD6482 on the expression of cyclin D1 are presented by western blot analysis.

The two cell lines were exposed to various concentrations of AZD6482 (0.625-40 $\mu \mathrm{M})$ for $48 \mathrm{~h}$. The results showed that the viability of the cell lines was significantly $(\mathrm{P}<0.0001)$ suppressed in a dose-dependent manner (Fig. 2B). The results also showed that U118 cells were more sensitive than U87 cells, with $\mathrm{IC}_{50}$ values of 7.989 (95\% CI, 6.5-9.7) and 9.061 (95\% CI, 7.5-11), respectively.

To further confirm the potential inhibitory action of AZD6482, a colony formation assay was carried out to assess proliferation. After three weeks of growth, the final counts of colonies treated with AZD6482 (U87: 21 clones; U118: 37 clones) were fewer than those of the non-treated cells (U87: 110 clones; U118: 78 clones, $\mathrm{P}<0.01)$ (Fig. 2C). In addition, a 5-ethynyl-2'-deoxyuridine (EdU) incorporation assay was performed with both U87 and U118 cells. The fluorescence images showed that the percentage of EdU-positive cells was decreased in a dose-dependent manner (Fig. 2D). This indicated that DNA replication was inhibited by AZD6482. These results, along with the viability data, confirmed the antiproliferative effect of AZD6482 on glioma cells.

AZD6482 induces apoptosis in U87 and U118 cells. To observe the influence of AZD6482 on cell apoptosis, flow cytometric analysis with PE/7-ADD staining was performed. After treatment with various concentrations of AZD6482, the results showed that the early apoptotic cell population (U87: 13.5\%; U118: 11.3\%) was increased in a dose-dependent manner (Fig. 3A and B). Moreover, western blot results showed that the expression level of Bcl-2 was downregulated with increasing drug concentration, and the expression level 
A
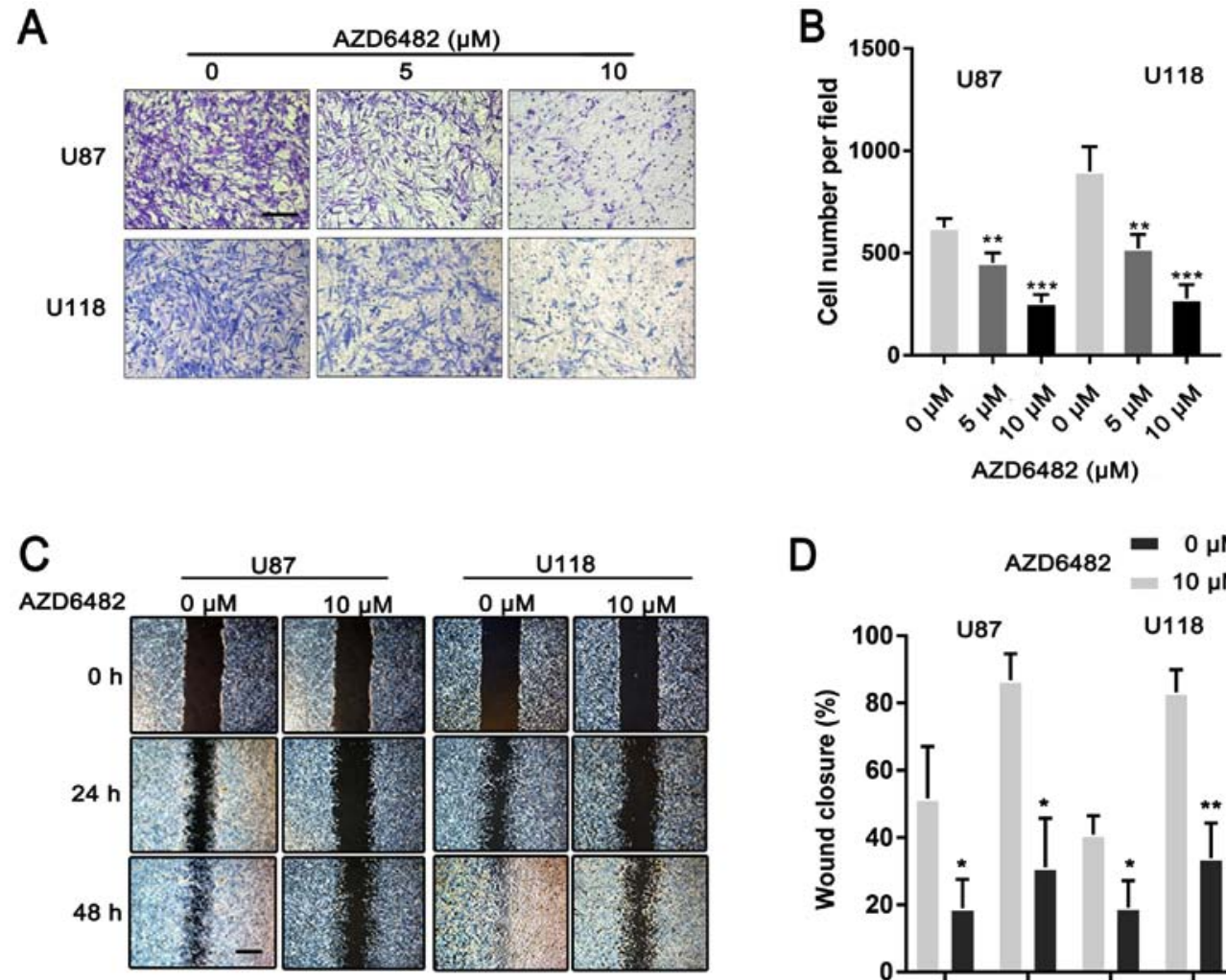

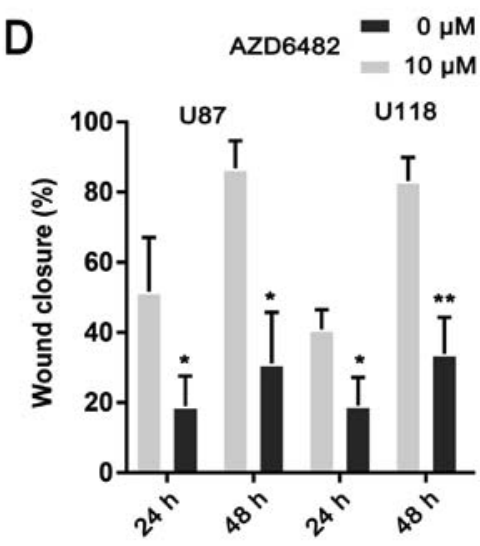

Figure 5. AZD6482 inhibits glioblastoma cell migration and invasion. (A) The invasion ability of U87 and U118 gradually decreased with increasing concentrations of AZD6482. Scale bar, $100 \mu \mathrm{m}$. (B) The invaded cells were counted under a light microscope. (C) The cell monolayer was wounded with a pipette tip and treated with 0 or $10 \mu \mathrm{M}$ AZD6482. Images were acquired at 0,24 , and $48 \mathrm{~h}$ in the wound-healing assay. Scale bar, 500 $\mu \mathrm{m}$. (D) The rate of wound closure in the AZD6482-treated group was lower than that in the untreated group at $48 \mathrm{~h}$ of growth. Data are presented as the means \pm SD of three independent experiments; ${ }^{*} \mathrm{P}<0.05,{ }^{* *} \mathrm{P}<0.01,{ }^{* * *} \mathrm{P}<0.001$, compared with the untreated controls $(0 \mu \mathrm{M})$.

of Bax was upregulated under the same conditions (Fig. 3C). The ratio of $\mathrm{Bcl}-2 / \mathrm{Bax}$ was also significantly decreased. It is well known that the PI3K-AKT signalling pathway is involved in cell survival. Western blotting was performed to confirm whether AZD6482 targeting of PI3K $\beta$ induced apoptosis by the PI3K-AKT signalling pathway. The results showed that the levels of p-AKT and p-GSK-3 $\beta$ were decreased in U87 and U118 cells (Fig. 3D) with increasing concentrations of AZD6482. These results further confirmed that AZD6482 induced apoptosis through the PI3K-AKT signalling pathway in U87 and U118 cells.

AZD6482 induces cell cycle arrest at the G1 phase in U87 cells. The cell cycle is also related to the viability of cells. The cells treated with various concentrations of AZD6282 for $48 \mathrm{~h}$ were stained with PI and analysed by flow cytometry. The results showed that AZD6482 induced G1 arrest in the U87 cells (Fig. 4A and B). However, no significant accumulation of U118 cells in the G1 phase was found. Meanwhile, previous studies reported that the expression of cyclin D1 is mediated by GSK-3 $\beta$ (21-23), and it was confirmed that the level of phosphorylation decreased after AZD6482 treatment (Fig. 4C). Therefore, AZD6482 induced G1 arrest in U87 cells via the PI3K-AKT signalling pathway.

AZD6482 inhibits the migration and invasion of U87 and U118 cells. To investigate the effect of AZD6482 on glioma metastasis, wound-healing and invasion assays were performed. Compared to the group treated with AZD6482, the untreated group demonstrated a rapid increase in the gap distance up to $48 \mathrm{~h}$ of growth (Fig. 5A and B). The cells treated with AZD6482 also demonstrated a significant reduction in invasive ability compared to the untreated cells (Fig. 5C and D). All of the results demonstrated that AZD6482 inhibited the migration and invasion of U87 and U118 cells.

\section{Discussion}

The PI3K signalling pathway is one of the most critical signalling pathways in a variety of human cancers $(24,25)$. Mutations in PIK3CA or PTEN are the most frequent genetic alterations in this pathway (9). Therefore, targeted PI3K inhibitors are potential anticancer drugs. Currently, targeted p110a drugs are developed faster than those targeting p110 $\beta$. However, previous studies have reported that $\mathrm{p} 110 \beta$ is thought to play a pivotal role in PTEN loss-induced tumourigenesis $(26,27)$. Herein, we showed for the first time that a p110 $\beta$-selective inhibitor, AZD6482, could inhibit the induced cell proliferation of glioma mediated by the loss of PTEN. Based on previous reports (28), U87 and U118 cell lines containing genomic mutations in PTEN were selected as the cell lines for this research. Then, we confirmed that AZD6482 suppressed the proliferation of $\mathrm{U} 87$ and $\mathrm{U} 118$ cells, with $\mathrm{IC}_{50}$ values of 9.061 and 7.989, respectively. AZD6482 not only promoted G1 
arrest and cell apoptosis but also had significant anticancer activity by inhibiting cell migration and invasion.

The cell cycle is known to be regulated by the cyclin-CDK complex and CDK inhibitor proteins. As a critical component of the G1/S checkpoint, cyclin D1 forms a complex with CDK4 and promotes cellular passage through the G1 phase $(29,30)$. Previous studies have indicated that GSK-3 $\beta$ increases the expression of cyclin D1, which is a downstream molecule of AKT. As shown in this study, treatment with AZD6482 led to a decrease in p-GSK-3 $\beta$ and p-AKT expression. Therefore, the G1 arrest of U87 cells might be due to AZD6482 blockade of the PI3K signalling pathway.

Flow cytometry with Annexin PE/7-ADD staining suggested that AZD6482 induced apoptosis in U87 and U118 cells, which affected cell proliferation. This result was also supported by the expression levels of Bcl-2 and Bax. Finally, the wound-healing and cell invasion assays confirmed that the migration and invasion of human glioma cell lines was reduced by AZD6482.

Although there were notable discoveries in this study, many limitations still exist. First, previous research demonstrated that the effects of $110 \beta$ inhibitors were transient and caused the activation of PI3K $\alpha$ and a rebound of downstream signalling in PTEN-deficient tumours (13). In our study, this rebound was not observed, perhaps because the drug treatment course was short. Second, animal experiments have not yet been implemented. Although some recent studies confirmed that the pharmacodynamics of AZD6482 are consistent in vivo and in vitro for some non-nervous system tumours (16), the consequence in glioma might be different due to the presence of the blood-brain barrier. Third, our data demonstrated that AZD6482 only affected PI3K signalling in PTEN-deficient glioma cell lines. Previous research confirmed that a few tumour cell lines with PTEN mutations and wild-type PTEN were sensitive to AZD6482 (15). However, whether AZD6482 has the same inhibition property in wild-type glioma cell lines needs to be further verified. Despite its limitations, this study indicates that AZD6482 is a promising drug candidate for glioma therapy.

\section{Acknowledgements}

Not applicable.

\section{Funding}

The present study was supported by grants from the National Science Foundation of China (no. 81572489).

\section{Availability of data and materials}

The datasets used during the present study are available from the corresponding author upon reasonable request.

\section{Authors' contributions}

PFX, JAY and QXC conceived and designed the study. PFX conducted the experiments. JAY and JHL performed the bioinformatics study and data interpretation. XY, JML, FEY and BHL performed the statistical analysis. PFX and JAY wrote the manuscript. JHL, XY, JML, FEY, BHL and QXC reviewed and edited the manuscript. All authors read and approved the manuscript and agree to be accountable for all aspects of the research in ensuring that the accuracy or integrity of any part of the work are appropriately investigated and resolved.

\section{Ethics approval and consent to participate}

Ethical approval was waived since we used only publicly available data and materials in this study.

\section{Patient consent for publication}

Not applicable.

\section{Competing interests}

The authors declare that they have no competing interest.

\section{References}

1. Louis DN, Perry A, Reifenberger G, von Deimling A, FigarellaBranger D, Cavenee WK, Ohgaki H, Wiestler OD, Kleihues P and Ellison DW: The 2016 World Health Organization Classification of Tumors of the Central Nervous System: A summary. Acta Neuropathol 131: 803-820, 2016.

2. Omuro A and DeAngelis LM: Glioblastoma and other malignant gliomas: A clinical review. JAMA 310: 1842-1850, 2013.

3. Alifieris C and Trafalis DT: Glioblastoma multiforme: Pathogenesis and treatment. Pharmacol Ther 152: 63-82, 2015.

4. Anjum K, Shagufta BI, Abbas SQ, Patel S, Khan I, Shah SAA, Akhter N and Hassan SSU: Current status and future therapeutic perspectives of glioblastoma multiforme (GBM) therapy: A review. Biomed Pharmacother 92: 681-689, 2017.

5. Aldape K, Zadeh G, Mansouri S, Reifenberger G and von Deimling A: Glioblastoma: Pathology, molecular mechanisms and markers. Acta Neuropathol 129: 829-848, 2015.

6. Network TC: Corrigendum: Comprehensive genomic characterization defines human glioblastoma genes and core pathways. Nature 494: 506, 2013

7. Vanhaesebroeck B, Guillermet-Guibert J, Graupera M and Bilanges B: The emerging mechanisms of isoform-specific PI3K signalling. Nat Rev Mol Cell Biol 11: 329-341, 2010.

8. Brennan CW, Verhaak RG, McKenna A,Campos B, NoushmehrH, Salama SR, Zheng S, Chakravarty D, Sanborn JZ, Berman SH, et al; TCGA Research Network: The somatic genomic landscape of glioblastoma. Cell 155: 462-477, 2013.

9. Avivar-Valderas A, McEwen R, Taheri-Ghahfarokhi A, Carnevalli LS, Hardaker EL, Maresca M, Hudson K, Harrington EA and Cruzalegui F: Functional significance of co-oc $\pi$ curring mutations in PIK3CA and MAP3K1 in breast cancer. Oncotarget 9: 21444-21458, 2018.

10. García-Escudero R, Segrelles C, Dueñas M, Pombo M, Ballestín C, Alonso-Riaño M, Nenclares P, Álvarez-Rodríguez R, Sánchez-Aniceto G, Ruíz-Alonso A, et al: Overexpression of PIK3CA in head and neck squamous cell carcinoma is associated with poor outcome and activation of the YAP pathway. Oral Oncol 79: 55-63, 2018.

11. Peyre M, Gaillard S, de Marcellus C, Giry M, Bielle F, Villa C, Boch AL, Loiseau H, Baussart B, Cazabat L, et al: Progestinassociated shift of meningioma mutational landscape. Ann Oncol 29: 681-686, 2018.

12. Schwartz S, Wongvipat J, Trigwell CB, Hancox U, Carver BS, Rodrik-Outmezguine V, Will M, Yellen P, de Stanchina E, Baselga J, et al: Feedback suppression of PI3K $\alpha$ signaling in PTEN-mutated tumors is relieved by selective inhibition of PI3K $\beta$. Cancer Cell 27: 109-122, 2015.

13. Yuzugullu H, Baitsch L, Von T, Steiner A, Tong H, Ni J, Clayton LK, Bronson R, Roberts TM, Gritsman K, et al: A PI3K p110 $\beta$-Rac signalling loop mediates Pten-loss-induced perturbation of haematopoiesis and leukaemogenesis. Nat Commun 6: 8501,2015 . 
14. Wee S, Wiederschain D, Maira SM, Loo A, Miller C, deBeaumont R, Stegmeier F, Yao YM and Lengauer C: PTEN-deficient cancers depend on PIK3CB. Proc Natl Acad Sci USA 105: 13057-13062, 2008

15. Ni J, Liu Q, Xie S, Carlson C, Von T, Vogel K, Riddle S, Benes C, Eck M, Roberts T, et al: Functional characterization of an isoform-selective inhibitor of PI3K-p110 $\beta$ as a potential anticancer agent. Cancer Discov 2: 425-433, 2012.

16. Gao J, Aksoy BA, Dogrusoz U, Dresdner G, Gross B, Sumer SO, Sun Y, Jacobsen A, Sinha R, Larsson E, et al: Integrative analysis of complex cancer genomics and clinical profiles using the cBioPortal. Sci Signal 6: pl1, 2013.

17. Cerami E, Gao J, Dogrusoz U, Gross BE, Sumer SO, Aksoy BA, Jacobsen A, Byrne CJ, Heuer ML, Larsson E, et al: The cBio cancer genomics portal: An open platform for exploring multidimensional cancer genomics data. Cancer Discov 2: 401-404, 2012.

18. Gu Z, Eils R and Schlesner M: Complex heatmaps reveal patterns and correlations in multidimensional genomic data. Bioinformatics 32: 2847-2849, 2016.

19. Yang W, Soares J, Greninger P, Edelman EJ, Lightfoot H, Forbes S, Bindal N, Beare D, Smith JA, Thompson IR, et al: Genomics of Drug Sensitivity in Cancer (GDSC): A resource for therapeutic biomarker discovery in cancer cells. Nucleic Acids Res 41: D955-D961, 2013.

20. Laco F, Woo TL, Zhong Q, Szmyd R, Ting S, Khan FJ, Chai CLL, Reuveny S, Chen A and Oh S: Unraveling the inconsistencies of cardiac differentiation efficiency induced by the GSK3 inhibitor CHIR99021 in human pluripotent stem cells. Stem Cell Reports 10: 1851-1866, 2018.

21. Liu SL, Liu Z, Zhang LD, Zhu HQ, Guo JH, Zhao M, Wu YL, Liu F and Gao FH: GSK3 $\beta$-dependent cyclin D1 and cyclin E1 degradation is indispensable for NVP-BEZ235 induced G0/G1 arrest in neuroblastoma cells. Cell Cycle 16: 2386-2395, 2017.

22. Wang J, Li XM, Bai Z, Chi BX, Wei Y and Chen X: Curcumol induces cell cycle arrest in colon cancer cells via reactive oxygen species and Akt/ GSK3 $3 /$ cyclin D1 pathway. J Ethnopharmacol 210: 1-9, 2018.
23. Lien EC, Dibble CC and Toker A: PI3K signaling in cancer: Beyond AKT. Curr Opin Cell Biol 45: 62-71, 2017.

24. Fruman DA, Chiu H, Hopkins BD, Bagrodia S, Cantley LC and Abraham RT: The PI3K pathway in human disease. Cell 170: 605-635, 2017.

25. Jia S, Liu Z, Zhang S, Liu P, Zhang L, Lee SH, Zhang J, Signoretti S, Loda M, Roberts TM, et al: Corrigendum: Essential roles of PI(3)K-p110 $\beta$ in cell growth, metabolism and tumorigenesis. Nature 533: 278, 2016.

26. Chen H, Mei L, Zhou L, Shen X, Guo C, Zheng Y, Zhu H, Zhu Y and Huang L: PTEN restoration and PIK3CB knockdown synergistically suppress glioblastoma growth in vitro and in xenografts. J Neurooncol 104: 155-167, 2011.

27. Mikheev AM, Mikheeva SA, Severs LJ, Funk CC, Huang L, McFaline-Figueroa JL, Schwensen J, Trapnell C, Price ND, Wong S, et al: Targeting TWIST1 through loss of function inhibits tumorigenicity of human glioblastoma. Mol Oncol 12: 1188-1202, 2018

28. Verreault M, Weppler SA, Stegeman A, Warburton C, Strutt D, Masin D and Bally MB: Combined RNAi-mediated suppression of Rictor and EGFR resulted in complete tumor regression in an orthotopic glioblastoma tumor model. PLoS One 8: e59597, 2013.

29. Malumbres M and Barbacid M: Cell cycle, CDKs and cancer: A changing paradigm. Nat Rev Cancer 9: 153-166, 2009.

30. Fedorov SN, Shubina LK, Bode AM, Stonik VA and Dong Z: Dactylone inhibits epidermal growth factor-induced transformation and phenotype expression of human cancer cells and induces G1-S arrest and apoptosis. Cancer Res 67: 5914-5920, 2007. International (CC BY-NC-ND 4.0) License. 